\title{
Novel Dramatic and Ludic Tensions arising from Mixed Reality Performance as exemplified in Better Than Life
}

\author{
Nicky Donald, Dr Marco Gillies and Annette Mees \\ Department of Computing/Institute for Creative and Cultural Entrepreneurship \\ Goldsmiths College, University of London SE14 6AS, UK \\ n.donald@gold.ac.uk, m.gillies@gold.ac.uk
}

\begin{abstract}
We observe that a Mixed Reality Performance called Better Than Life gave rise to novel dramaturgical and ludic possibilities that have not been observed elsewhere. Mixed Reality Performance is an emergent genre that takes many forms, in this case a live experience for a small group of physical participants (PP) and a larger group of online participants (OP). Both groups were offered individual and collective interactions that altered the narrative in real time. A mixed methodology approach to data generated during the performance has identified two key moments where both physical and online participant groups are split into many subgroups by ongoing live events. These events cause tensions that affect the trajectories of participants that make up their experience. Drawing on literary, theatre, cinema and digital game criticism we suggest that the possibilities for engagement in Mixed Reality Performance are exponentially greater than those available to previous media.
\end{abstract}

Keywords: interactive storytelling, mixed reality, live streaming, real-time interaction

\section{Introduction}

This paper is not concerned with the core research questions, findings, or user data, both quantitative and qualitative, gathered during the Better Than Life project. All this and more is contained in the official NESTA report which can be found here: artsdigitalrnd.org.uk/projects/coney. This paper is concerned with two particularly novel and complex moments that have no real equivalent elsewhere.

Mixed Reality Performance covers a small number of diverse experiments over the last decade, notably by Blast Theory [3], covering overlapping areas of game, performance and installation. Punchdrunk and MIT's collaboration on Sleep No More ${ }^{l}$ also comes under this rubric. As a rule, participants navigate virtual spaces and content that coincide with physical spaces. Historically, this definition could well be ap-

\footnotetext{
${ }^{1}$ Artsdigitalrnd.org.uk/wp-content/uploads/2013/07/Academic-report_Punchdrunk.pdf

adfa, p. 1, 2011.

(C) Springer-Verlag Berlin Heidelberg 2011
} 
plied to television programmes such as The Adventure Game ${ }^{2}$ and Knightmare ${ }^{3}$ and empirically to any performances that use large-scale automation plotted in a 3-D model of the performance space. Suffice to say that the genre is emergent.

Better Than Life was a series of 845 -minute live Mixed Reality performances held in a Victorian glasshouse in New Cross in June 2014. It was funded by the NESTA Arts Digital R \& D fund and devised by Coney in partnership with Goldsmiths College and Showcaster. Live broadcast production was by Spirit Digital, set design and construction by Pan Studios in collaboration with consultant magician Jon Armstrong. Coney are "interactive theatre-makers" with a long history of creating experiences for adults and children in settings from royal palaces to classrooms. Showcaster specialised in live streaming events for corporate customers and national media organisations. They have since transferred their activities to the Grabyo platform.

The premise was to host a live piece of immersive theatre, somewhere between a game show and a drama, live-streamed to an online audience and offering real-time interactions to both the physical participants on set and to the online participants at home. For the purposes of this paper I will refer to the audience who were present at the venue as the Physical Participants (PP) and those who took part online as the Online Participants (OP). This distinction is needed as the terminology remains unclear even among the most experienced practitioners of mixed reality and interactive television [14]. From the outset the intention was to provide complementary experiences, simultaneous but divergent, for PP and OP. At the end of the show the two groups would be able to engage directly with each other and compare their experiences.

\section{The User Interface}

Online Participants were presented with a live video feed and a chat box. It was possible to go full-screen but this removed the chat interface. Underneath the video were 5 buttons which would switch between:

a) the video mix, a live edit of the camera streams which was much like a conventional broadcast, switching between various fixed and roaming cameras

b) Camera 1, a roaming, handheld camera

c) Camera 2, a second roaming, handheld camera

d) the Commentary camera, a fixed view of the commentator

e) the Audience Cam, a third roaming camera which moved closely to the PP groups and caught conversations

Hidden in the logo was a button enabling the Secret Camera, activated at certain key moments. Once activated, a Secret Camera button appeared alongside the others.

\footnotetext{
${ }^{2}$ The Adventure Game BBCTV, UK 1980

${ }^{3}$ Knightmare ITV, UK 1987
} 


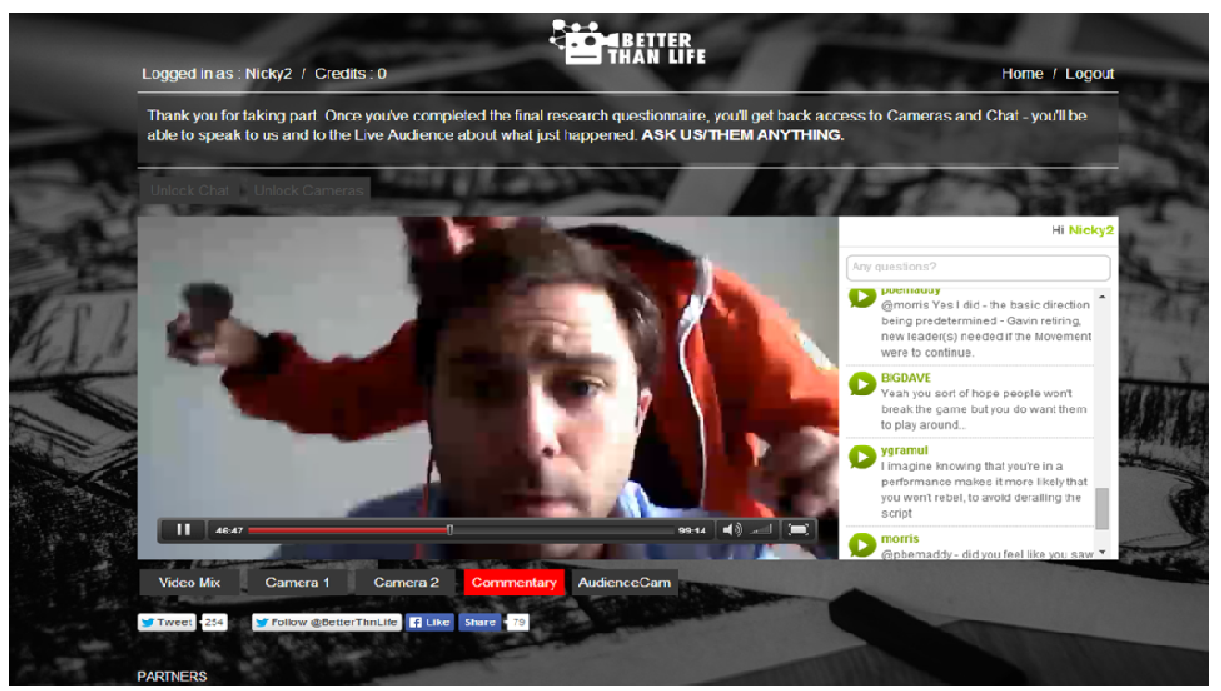

Fig. 1 The user interface

\section{Scenario and interactions}

The scenario, briefly, was that a tiny cult were looking for new recruits. Their leader, the clairvoyant Gavin, knows that today he will solve all world problems and disappear to a higher plane. His followers, the idealist Tommy and the ambitious Shipra, canvass for new members and test them for psychic abilities. Initially, the Online Participants can chat only to each other and Big Dave, the fictional moderator. Once the tests are underway, the Online Participants follow the Physical Participants via various fixed and roaming cameras, switching between them at will. On a separate camera they find the Commentator, a fictional anthropologist who provides further insight into the unfolding events and their background. Following hints given by Tommy to camera and by Big Dave in the chat room, some Online Participants gain access to the Secret Camera, where Gavin appears and lets them know that the whole performance is something of a sham that he has allowed to get out of hand with the intention of embarrassing Shipra. At this stage, the fictional characters Gavin and Tommy are reading and responding in real time to chat messages from the Online Participants. Gavin lets the Online Participants choose his costume and give him lines to use in his entrance speech.

At the end of the show, having saved the world, Gavin magically disappears in front of everyone and a new leader is chosen by the Online Participants as the Physical Participants and fictional characters argue their case for taking over and continuing or abandoning the cult. Here individual Present Participants address the Online Participants directly and the Online Participants discuss their arguments.

After the show, we encouraged groups of PP to talk directly to OP by means of a large screen which showed the video feed and the chat area. OP were able to chat 
directly to PP who replied to camera. Between them, they built up an overall picture of the storyworld and shared their diverse experiences. This environment was known as the "bar".

\section{Methodology- capture and analysis}

All of the live stream video was recorded, from six different cameras. Over the course of the project, over 1000 hours of video was generated. We also logged thousands of actions; every chat message and every time a user switched between camera views. Physical participants were given questionnaires before and after the show and online participants were given short questionnaires at three points during the show. The aftershow conversations between PP and OP were transcribed. Once all these were collated we were able to see how individuals felt about the experience and trace their trajectory through the show, punctuated by their own commentary. In this paper we are concerned with two key sequences that, having arisen from the process of data analysis, show the larger forces at that shape those experiences and trajectories. We arrived at these sequences by the following methods:

1) visualising the user paths between the camera streams, revealing individual paths through the show, collective movements and numbers of OP that witnessed particular events

2) coding the chat messages and transcriptions, looking for particular interactions such as direct address to actors, groups or individuals within PP and OP

3) tracking down and closely analysing particular moments in the video footage that the previous two methods suggested to be of interest

\section{Theoretical background}

We suggest that beyond the theory of individual trajectories [3] there lies a language of tensions based on the sharing and withholding of information between individuals and groups within the sets comprised of online, physical, real and fictional participants. We will also use the lenses of metalepsis, metatheatre and framing from literary and dramaturgical theory.

\section{$5.1 \quad$ Trajectories}

"Mixed Reality Performance[s]... are constituted by a number of embedded and emergent trajectories through... a complex mixture of space, time, interfaces, and performance roles that are connected into a sophisticated structure using computing technologies"[3]

We cannot situate these sets (actors, PP, OP and subsets) along a linear continuum starting with physical participation at one end and virtual participation at the other. BTL employed fictional characters (actors, or NPCs in digital game parlance) in the physical performance space, in the virtual space of the Chat room and in the fictional 
space of the commentary room. Online Participants (OP) occupied all of these spaces and the Physical Participants (PP) became aware of them over time. Indeed several Physical Participants returned as Online Participants. The theory of trajectories helps us to map these spaces in some way. If we trajectorise the experience of the actor playing Gavin alongside those of the physical and online participants, we begin to see distinct states of being, transitions, and intangible seams that hint at a complex structure that can only be revealed by further experimentation.

\subsection{Weird Archaeology}

"the documentation of unwritten happening, attested through material trace, is an archaeological project" [18]

If the interaction, chat and video data are the material traces of the performance, we are engaged in kind of Lovecraftian archaeology, uncovering a structure that is of unknown and quite possibly "inconceivable shape"[15]. By examining the material traces we begin to see edges, interstices and planes, adjacencies and superimpositions [3]. We send probes in the form of participants and track their progress, their recollections and reactions. The set of participants must also include those previously classed as actors and technicians, since they are very much part of the whole each time it is in motion. In BTL technicians were frequently on camera and on occasion dragged into the fictional world. For example, when a technician is addressed by a fictional character on camera, (s)he slides between the real, mediated and fictional worlds. This is doubly confounding when the technician is habitually invisible in the real world; several intangible, invisible boundaries are broken at once between conventions and cognitive states.. Mapping the structure in which these boundaries lie is surely an exercise in "weird ontography" [10].

\subsection{Narrative and Dramatic Tensions}

The wider picture can be glimpsed in terms of the narrative, dramatic, ludic and indeed technological devices BTL used to engage participants. Dramatic and narrative tensions arise from the author(s) withholding and gradually divulging information to the audience. Consider books, plays and films in the mystery genre where the author plays with the reader/spectator's expectations and the reader/spectator attempts to second-guess the author using the information available. This is linear, narrative tension and recently has given rise to a ludic approach to literature informed by Interactive Fiction $[16,19]$ and to film criticism informed by digital games [20].

The playwright David Edgar identifies differential knowledge as the key mechanism for generating tension and engagement in theatre:

"differential knowledge, the root of dramatic or proleptic irony (dramatic, when the audience knows something but a significant character doesn't; proleptic, when none of characters know what's going on [but the audience is aware that the play is a tragedy, a comedy etc])...the difference between what we know and what the characters know is not just a mechanism for unfolding the plot but also the expression of the play's fundamental meaning." [7] 
In Better Than Life, information was withheld and divulged by subsets of actors and participants alike. These transactions are analysed in detail in section 7 .

\section{The Ludic Methodology: Losing control}

Over eight shows BTL gave rise to hundreds of questionnaire responses, thousands of chat messages, thousands of channel switches and hundreds of hours of video. All had to be scrutinised to find single revelatory moments that were not at all apparent to researchers on the scene. During a live show we were far too busy maintaining the interaction systems and live streams to follow dialogue, user activity or even narrative; we were simply a part of a frenzied whole.

However this is a powerful insight in itself; a Ludic methodology is a framework allowing sufficient play for moments of transcendence. Only when the authors, technicians and researchers lose control of participants can they play freely; it is only when rules are broken that we perceive their fragility and their validity, if any. Myers insists that "breaking gamerules is necessary to establish the presence and... function of rules" [17]. Ludic methodology consists not of establishing rules but testing the boundaries and breaking points of any given system. The philosophy of Myers' "bad" [17] or Spariosou's "destructive" [25] play supports our position, namely that Dionysian play in its transgression of social norms is the best way to inspect and maintain the structure of society, a game or a storyworld. As engineers or bricoleurs, we test things until they break and rebuild them in the light of that knowledge. In the two key sequences examined in this paper, an experienced player breaks the rules.

\section{$7 \quad$ Metalepsis}

It is only when Gavin breaks the rules of the story and of the game that we see the illusory boundaries within which we have been working. Thus far, we have two rich, revelatory transgressions in BTL. After weeks of analysis, linking chat messages with channel switching, 15 seconds of video were located. When Gavin attacks the Commentator he breaks the rules of the storyworld. Months later, the same analysis led to another 15-second sequence. When Gavin attacks the physical audience he breaks the rules of the spectacle as a whole.

Metalepsis was first identified by Gerard Genette in Homer, Diderot and Sterne :"taking hold of (telling) by changing level...the narrator pretends to enter (with or without the reader) into the diegetic universe"[9]. In Umberto Eco's The Prague Cemetery, the narrator gradually discovers that he is the protagonist [6]. It has since been applied to the metatheatre of Genet and Pirandello and to cinema classics such as The Last Remake of Beau Geste ${ }^{4}$, where characters move between the diegetic world of a story and the extradiegetic world of its supposed telling. The Last Remake of Beau Geste contains two levels of metalepsis. In a café, Marty Feldman shares a

\footnotetext{
${ }^{4}$ The Last Remake of Beau Geste. Marty Feldman, Universal Pictures, US (1977)
} 
joint with Gary Cooper who is playing his brother in a different (black and white) version of the film. At another point, Feldman appears alongside the spinning globe of the Universal logo, pulls the letters off and sticks his finger into the Sahara, creating a gigantic hole into which marching foreign legionaries fall.

The first is a character moving between storyworlds. The second is a character breaking out into the real world of logos and production credits in which we, the audience, live. The former, to paraphrase Marie-Laure Ryan [22], is a rhetorical metalepsis and the latter an ontological one. Consider the parallels with the two attacks in Better Than Life:

Gavin moves from the world of the cult to that of the commentator, revealing him as both both collocated and fictional. In the second instance, Gavin moves from the fictional world of the story to the "real" world of free, unscripted conversation between the PP and OP. This is the penultimate metalepsis; the ultimate would be Gavin appearing in your home, something hinted at when Gavin magically disappears (a Pepper's Ghost illusion characterised as metaleptic by Kukkonen \& Klimek [13]).

There are ludic possibilities for metalepsis, allowing participants to move between diegetic levels. Astrid Ensslin has identified interactional metalepsis as an "underresearched area" [8], but there are precedents in Live Action Role Play (LARP). Players meet at a location and play fictional characters, sometimes for days at a time. The Nordic tradition allows for the "meta-room", where a participant steps out of the storyworld to explore the inner workings of their character's emotions and motivations with directors or other players: "If a player needed a scene he or she could enter the black box and order the scene he or she wanted." [12] In this case, a character can choose to move from the ongoing storyworld to an adjacent one. In Better Than Life, the Secret Camera was used as a similar device, where Gavin, Tommy and Shipra gave voice to their inner feelings and misgivings while the main action proceeded on other cameras.

\subsection{Gavin attacks the Commentator: rhetorical metalepsis, trajectory of information}

Like a sports commentator at a game, the Commentator appears to be watching at a remove. Once Gavin has crossed into this space (figure 1) it is revealed as part of the fiction and the spectacle is broken, expanded and ultimately reinforced. It is a rhetorical metalepsis, "a small window that allows a quick glance across levels, but the window closes ... and the operation ends up reasserting the existence of the boundaries" [22] However, in doing so he splits the participants: a set (A) of Online Participants see the attack on Commentator Camera and are aware of Gavin's actions, and a set who are not (B), comprising Online, Physical and fictional participants along with the technical team. Set A is further split: some heard Gavin stating his intention on one camera and followed him to the other in order to see the action (A1); some were watching the Commentator and shared his surprise and shock at the attack (A2). Their trajectories and experiences are quite different: A1 are in-the-know and complicit, in as much as they do not warn anyone of the impending attack. A2 are surprised like the actor playing the Commentator, who genuinely didn't know it was going to happen. 
This is a revelatory mixed reality moment, where some of the online audience (A2) share in the surprise of an actor and some (A1) are complicit with another. This moment then plays out in interesting ways. To reveal the emergent structure, we have to follow the trajectory of the information itself rather than the actants.

Group A shares this information with other Online Participants by chat message and subsequently with several Physical Participants in aftershow conversation at the "bar", where PP talked to camera and viewed OP responses on a monitor. Some OP were watching on fullscreen and never saw the messages. Most of the PP never knew about it since they were not party to that "bar" conversation. Most of the technical team remain unaware of it to this day since the researchers only found it weeks later.

While the attack made an impression on those watching it, it had little narrative consequence. However, a differential of information [7] occurred that remains full of potential. The attack happened, and the way in which that scene's content was distributed, the way that information was divulged and withheld, the trajectory of the information, is a profound insight into possible dramatic and ludic tensions for future Mixed Reality performances.

7.2 When Gavin attacks people after the show: ontological metalepsis and the transformation of the participant

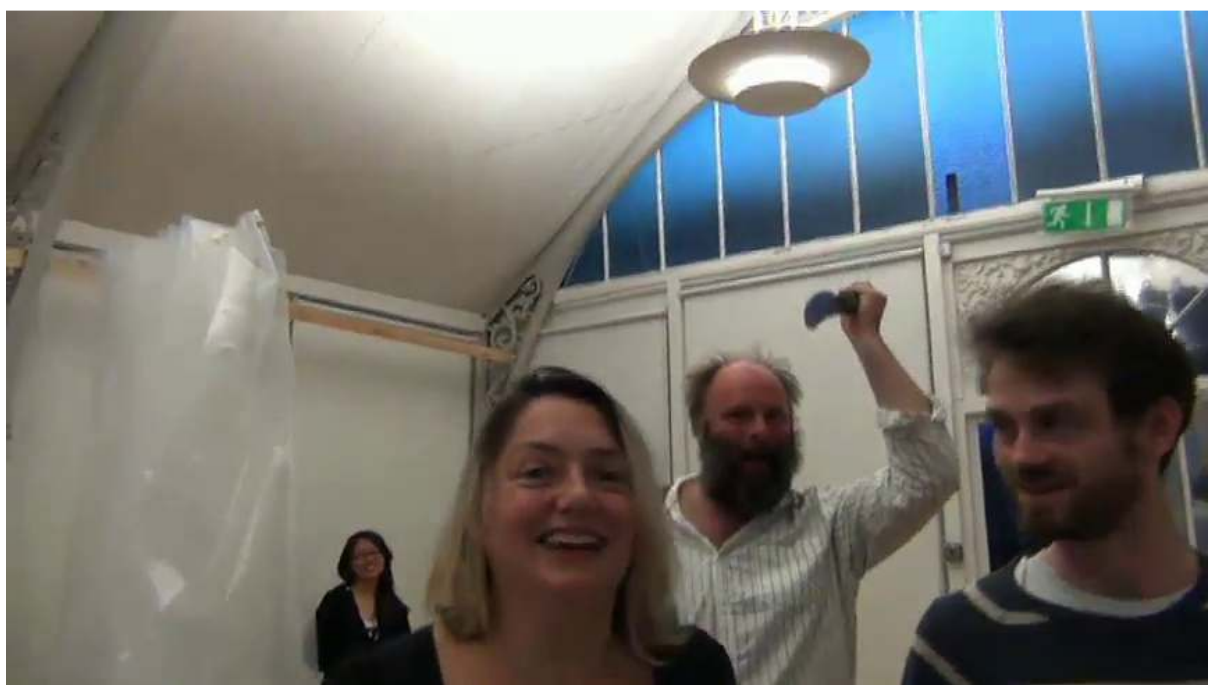

Figure 2: Gavin, centre, threatens an unwitting physical participant (left) and his own author (right) while a camera operator (far left) watches. Two more physical participants are seated out of shot to the right.

Our richest moment of insight, however is when Gavin threatens the Physical Participants. This is an ontological metalepsis, one of Hofstadter's strange loops in action:

"there is a shift from one level of abstraction (or structure) to another, which feels like an upwards movement in a hierarchy, and yet somehow the successive "upward" shifts turn out to give rise to a closed cycle." [11] 
In the film Nightmare on Elm Street ${ }^{5}$, the killer Freddy Krueger moves from the characters' dreams to their waking world. In the video game Alan Wake ${ }^{6}$ the writer is pursued by villains from his own oeuvre. Thankfully Freddy does not appear next to you in the cinema, nor do Alan Wake's villains appear in your living room. In Better Than Life, Gavin achieves a step in this direction.

In her analysis of metalepsis in drama, Marie-Laure Ryan examines the possibility of "metaleptic bleeding of the textual world into...the ground level of reality"[22] and concludes this is only possible if an actor uses a real knife during a show, superimposing a real murder on a scripted one. Luckily the actor playing Gavin is not inclined to murder, but there is a quite unprecedented leap between the fictional and real, the mediated and the live.

The show is finished. PP \& OP are discussing the spectacle they have just experienced. People are no longer performing; they are discussing their experience with each other and one of the authors, Tom Bowtell,. It is at this point that the fictional character Gavin reappears, provoking not only a fascinating mixed-reality interaction but causing completely unexpected rifts within the physical participants involved.

At a narrative, dramatic and ludic level the online participants (OP) suddenly have information that they desperately want to share with the physical participants (PP) on camera, namely that Gavin is behind them with a machete. However, the live stream is not entirely live; the events one sees on screen have happened up to a minute ago, dependent on server speed, ISP load, the equipment and local connection used to view. So, even though the OP send their warning message the moment Gavin appears, there is a fascinating 20 seconds before the physical participants receive the information, turn and see that he has gone, in best pantomime fashion ${ }^{7}$. The OP watch helplessly, which is doubly frustrating following a show in which they have been offered increasing levels of direct agency. There are innumerable ludic possibilities in exploiting this tension between immediacy and latency, between agency and passivity. It is a fascinating, exciting moment where the artistic process, the momentum of performance and our data capture and analysis come together to reveal an aspect of the future.

Just as fascinating is the reaction of the two PP who are seated off camera and have seen the whole thing. From transcription, we know that one of them recognizes Gavin from the show, the other does not. Both remain silent, prevented from acting by a perceived taboo. Were they at a bus stop they would presumably act quite differently. However both of them instantly perceive a tacit framework, namely that they are once more part of a show and that to intervene would somehow spoil the action. The first participant recognises Gavin and enters into a complicity with his joke. The second

\footnotetext{
${ }^{5}$ A Nightmare on Elm St. Wes Craven, New Line Cinema, US (1984)

${ }^{6}$ Alan Wake. Remedy Entertainment, Finland ( 2010)

7 In the UK, a traditional Xmas panto is a theatre show invariably including a sequence where the villain appears behind the hero, prompting the audience to cry out "he's behind you!" The hero turns but the villain has hidden. The hero berates the audience for interrupting, then the sequence is repeated
} 
offscreen physical participant fails to recognize Gavin but recognises that aberrant behaviour is expected, that normal social responsibilities do not now apply. Unprompted, she transforms herself into a spectator. This is a brilliant and unplanned illustration of Ranciere's argument that there is no static opposition between acting and spectating, that the spectacle is subject to constant individual interpretation, where the viewer links the action before them with their own social and cultural experience, with every story they have been through and been told, and reacts accordingly [21].

Just as we do not expect a conventional theatre audience to intervene in dramatic events, it is likely most people would perceive the emergent rules of this situation and fail to intervene. Indeed a great deal of stage magic is based on this premise; perceived social pressure inhibits the audience member from contradicting the magician's version of events [26]. This is a human frailty; just as we instinctively, inevitably construct causality $[24,28]$, we construct rules for our behaviour on-the-fly.

\section{Conclusion and Further Enquiry}

Mixed Reality Performance demands a mixed approach, combining hard data with anecdote. Although Benson \& Giannachi's trajectory-based analysis provides excellent results it is insufficient. Our participants are our probes; we track their progress, their recollections and reactions. But these trajectories are poor things in themselves. Like caterpillars in cabbages, we can see layers but not the shape of the leaf, still less the arrangement of the whole, its symmetries and situation. This is not to say that trajectorising the participant experience is not a crucial tool in understanding the mixed reality medium. In fact all of our current insights arise from this process. Only by following the movements of real and fictional, physical and virtual participants can we reach the waypoints that give rise to insight.

Nevertheless an understanding of narrative, dramatic and ludic structures and devices helps us to understand the forces at play across the whole experience, the tensions that influence the trajectories. As we examine the hard data, we can detect the influence of these tensions and improve our understanding of the whole. This in turn helps us to design experiences that take better advantage of these forces.

For example, Better Than Life allowed for infrequent communication between Physical and Online Participants. If both PP and OP were to use Twitter, communication would improve, but the live experience would be punctuated by PP consulting their phones. Furthermore, any information shared by the OP is immediately available to the PP, so differential information mechanics are unavailable. Improved communication has direct dramatic and ludic consequences, itself evidence of various tensions at work.

We do not attempt a universal list of possible tensions in a mixed reality environment Chris Salter identifies a mixed reality tension as early as 1924 in Erwin Piscator's Trotz Allem. Piscator himself recollects "the dramatic tension that live scene and film clip derived from one another." [23] 
In The Emancipated Spectator Rancière proposes that we re-examine assumed "equivalences between theatrical audience and community, gaze and passivity, exteriority and separation, mediation and simulacrum; oppositions between the collective and the individual, the image and living reality, activity and passivity, self-ownership and alienation." [21] In Better Than Life, participants, actors and technicians alike moved elliptically between these states.

Maintaining tension sustains engagement. We admitted earlier that the technical team, researchers and authors were involved in frenzied activity throughout the shows, so there was no-one directing the action, controlling those tensions during the show. It is tempting to look to an Artifical Intelligence solution, and there are notable examples. Szilas and Richle have examined the control of dramatic tension in digital games: "Modelling tension... implies the construction of a computational model of the dramatic tension. This is different from tagging events with a tension level, as in the interactive drama Façade. The tagging approach only works when narrative events are not generated but prewritten"'[27]

The best known example of dynamic AI control of tension in digital games is the "AI Director" in Left4Dead (Valve 2008), which adapts the pressure on the players according to ability, creating crescendoes of action followed by periods of calm to great dramatic effect. Valve originally gave the AI some scenographic control in the sequel, adding to the tension of navigation: "the ability for the AI Director to change the path of the survivors through a level, so they have to take a different path each time." This advance was mitigated, however, by user testing: "playtesters found the paths confusing... having all paths open led to a better experience" [5].

As Mixed Reality Performance offers increasing numbers of physical, online and virtual participants increasing control over scenic and narrative elements in real and virtual spaces, there will have to be increased automation. However we suggest that an AI approach to controlling mixed reality tensions will generate a tension of its own, namely that between a coherent experience and one that allows for transgression. In this we echo Weyrauch's 1997 proposal on AI drama management systems arising from the Oz project: "that the artist give up direct control of the sequence of events and instead define the interactive drama with a destiny."[29]

\section{References \\ Texts}

1. Allain, Sébastien \& Szilas, Nicolas: Exploration de la métalepse dans les "serious games" narratifs, Revue STICEF, Volume 19 http://sticef.org (2012)

2. Ayckbourn, Alan: The Crafty Art of Playmaking. Faber \& Faber, London (2002)

3. Benford, Steve \& Giannachi, Gabriella: Performing Mixed Reality. MIT Press, Cambridge, Mass (2011)

4. Boyd, Frank: Immersive Media: To the Holodeck and Beyond, Knowledge Transfer Network blog post www.ktn-uk.co.uk/immersive-media-to-the-holodeck-and-beyond/ $06 / 06 / 2015$

5. Developer Commentary, Left 4 Dead 2, (2009 Video Game) Valve Software http://left4dead.wikia.com/wiki/Developer_Commentary_(Left_4_Dead_2) (2009)

6. Eco, Umberto \& Dixon, R. (trans.): The Prague Cemetery. Random House, London (2011) 
7. Edgar, David: How Plays Work. Nick Hern Books, London 2009

8. Ensslin, Astrid: Diegetic Exposure and Cybernetic Performance: Towards Interctional Metalepsis. Plenary presented at Staging Illusion: Digital and Cultural Fantasy, University of Sussex 8-9 December 2011

9. Genette, Gerard \& Lewin, Jane (trans.): Narrative Discourse: An Essay in Method. Cornell University Press, Ithaca (1983)

10. Harman, Graham : Weird Realism:Lovecraft and Philosophy. Zero Books, Croydon (2012)

11. Hofstadter, Douglas: I am a Strange Loop. Basic Books, New York (2007)

12. Hultman, Anders, Westerling, Anna \& Wrigstad, Tobias: Behind the Façade of a Nice Evening with the Family. In Playgrounds Worlds: Creating and evaluating Experiences of Role-Playing Games. Ropecon ry, Helsinki (2008)

13. Kukonnen, Karin \& Klimek, Sonja (eds): Metalepsis in Popular Culture. Walter de Gruyter, Berlin (2011)

14. Jenkes, Catherine: Presentation at NESTA Arts Digital R \&D Learning Day 11/06/15

15. Lovecraft, H.P.: The Dreams in the Witch House and Other Weird Stories. Penguin, New York (2004)

16. Montfort. N.: Twisty Little Passages: an approach to interactive fiction. The MIT Press, London (2003)

17. Myers, David: What's Good About Bad Play. In Proceedings of the second Australasian Conference on Interactive Entertainment p133-140. Creativity \& Cognition Press, Sydney (2005)

18. Pearson, Mike and Shanks, Michael: Theatre/Archaeology. Routledge, Padstow (2009)

19. Pereira, Joe: A Narrative at War with a Crossword - An Introduction to Interactive Fiction. In Expectations Eclipsed in Foreign Language Education: learners and educators on an ongoing journey. Sabancı Üniversitesi, İstanbul (2011)

20. Perron, Bernard: Présentation. L'entre-jeux : médiations ludiques. Intermédialités : histoire et théorie des arts, des lettres et des techniques / Intermediality: History and Theory of the Arts, Literature and Technologies, $\mathrm{n}^{\circ}$ 9, 2007, p9-13. URI: http://id.erudit.org/iderudit/1005526ar (2007)

21. Ranciere, Jacques: The Emancipated Spectator. Verso, London (2009)

22. Ryan, Marie-Laure: Avatars of Story (Electronic Mediations). University of Minnesota Press, Minneapolis (2006)

23. Salter, Chris: Entangled: Technology and the Transformation of Performance. MIT Press, Cambridge, Mass (2010)

24. Shermer, Michael: The Believing Brain: From Spiritual Faiths to Political ConvictionsHow We Construct Beliefs and Reinforce Them as Truths. Robinson, London (2011)

25. Spariosou, Mihai: Dionysus Reborn: Play and the Aesthetic Dimension in Modern Philosophical and Scientific Discourse. Cornell University Press, Ithaca (1989)

26. Steinmeyer, Jim: Hiding the Elephant: How Magicians Invented the Impossible. Arrow, London (2005)

27. Szilas, N., Richle, U.: Towards a Computational Model of Dramatic Tension. In M. A. Finlayson, B. Fisseni, B. Löwe and J. C. Meister (Eds.) Proc. Of the 2013 Workshop on Computational Models of Narrative, Aug. 4-6 2013, Hamburg, Gernamy, OASICS, Volume 32 (2013)

28. Wegner, Daniel: The Illusion of Conscious Will. MIT Press, London (2002)

29. Weyhrauch, Peter: Guiding Interactive Drama. PhD Thesis, Carnegie Mellon University, Pittsburgh (1997) 